Brit. J. vener. Dis. (1963), 39, 87.

\title{
SYPHILIS AND SISYPHUS*†
}

\author{
BY
}

\section{IRA LEO SCHAMBERG}

Special Consultant in Venereal Diseases, United States Public Health Service, Assistant Professor of Dermatology, School of Medicine and Graduate School of Medicine, University of Pennsylvania, Senior Attending Dermatologist, Albert Einstein Medical Center, Philadelphia

The incidence curve of infectious syphilis during the past 15 years may be likened to a cycle in the travail of Sisyphus, an ancient Corinthian king, who was condemned by Pluto to the task of rolling a huge stone to the top of a high hill, only to have it roll down again just as he reached the top.

In the United States the 20th century has seen three major campaigns against syphilis. The first followed the development of the complementfixation test for syphilis in 1906 and the synthesis of potent treponemicidal arsenical compounds in 1910. Wassermann had found the way to identify the targets for Ehrlich's "magic bullets". "Cases of syphilis can be rendered practically non-infective in a day or two. Ehrlich will have swept away the scourge of 2,000 years" (McIntosh and Fildes, 1910). "Syphilis could be eradicated from civilized humanity in two or three decades. What a hope, what a dream!" (Meltzer, 1910). Unfortunately, these glowing prophecies were not borne out.

Dr. Thomas Parran, then Surgeon General of the U.S. Public Health Service, set into motion the second attack on syphilis in 1937, and through a vigorous public health campaign many thousands of syphilitics were discovered and treated. Nonetheless, with the advent of World War II the attack rate of syphilis climbed steeply, and in 1947 over 106,000 cases of primary and secondary syphilis were reported.

The discovery by Mahoney, Arnold, and Harris (1943) of the effectiveness of penicillin in syphilis signalled the third great campaign. It was found that early syphilis could be cured in a matter of days, and in 10 years (1947-1957) the reported cases of primary and secondary syphilis plummetted 94 per cent. from a post-war peak of 106,539 to a mere 6,251 . It appeared that the battle was all but won,

* Received for publication November 19, 1962

+ Presented at the XII International Congress of Dermatology, Washington, D.C., September 9-15, 1962. but in 1957 the tide turned again. Fig. 1 demonstrates how the precipitous post-war decline to the valley of 1957 was followed by a three-fold increase in the 5 succeeding years from the 6,251 of 1957 to 20,084 in 1962. (It is of interest that, although reported cases of primary and secondary syphilis increased by 50.6 per cent. from 1960 to 1961 , they increased by only 7 per cent. from 1961 to 1962 .) A similar change has been noted throughout the world. Guthe (1962) reported that in 71 per cent. of 105 countries the attack rate of syphilis had increased since 1956 or 1957.

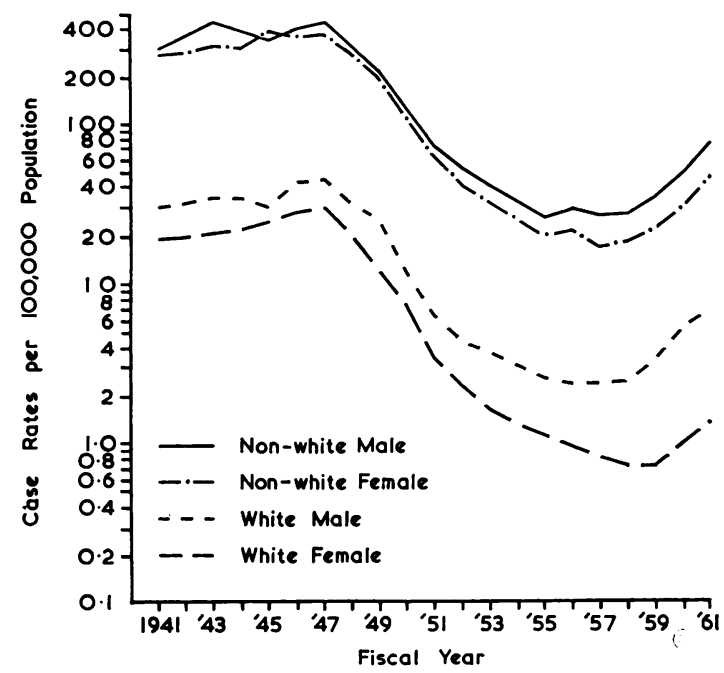

FIG. 1.- Incidence of primary and secondary syphilis per 100,000 population in the U.S.A., by sex and race, fiscal years 1941-61.

Health officers in 34 of 52 states (including Puerto Rico and the Virgin Islands) and in 67 of 107 cities believe that the recent apparent increase in syphilis is primarily due to an actual increase in incidence 
(Association of State and Territorial Health Officers, etc., 1962). However, this feeling is not universal. It has been suggested that what we are seeing is an epidemic of reports and not an epidemic of disease, and Shapiro expressed the opinion "that the reported incidence of disease by and large varies directly with monies appropriated to eradicate, contain, or stamp it out".

What measuring rods other than civilian incidence rates may be of significance? Annual syphilis incidence rates in the U.S. Navy and Marine Corps had not risen appreciably up to the end of September, 1962, above the rates in the early fifties (U.S. Navy, 1962). These rates may have more validity than civilian rates, since reporting in the armed services is probably more complete than among civilians. We have been unable to obtain rates for the Army and Air Force.

Crude sero-positivity rates are poor indices of the prevalence of syphilis, and even poorer indices of incidence. They are affected by many factors, among which are the amount of medical interest in syphilis and the numbers of tests performed in diagnosis and in post-treatment follow-up. However, they should be of value as indices of prevalence when performed on random samples of the population. Pre-marital serological tests in those States where they are required by law are not performed on a truly random sample, as common law marriages and even less formal and less permanent arrangements are common, especially in the lower socio-economic groups in which syphilis is more frequently seen (Schamberg, 1945). However, it is germane to look at the pre-marital and pre-natal sero-reactivity rates which have been made available to us. In all cases "seroreactive" includes reactive and weakly reactive. In Fig. 2 (State Depts. of Health, 1962) no clear universal trend in pre-marital sero-positivity rates is apparent. Only in Georgia, Alabama, and Ohio did the rate fall steeply during the early fifties, and only in

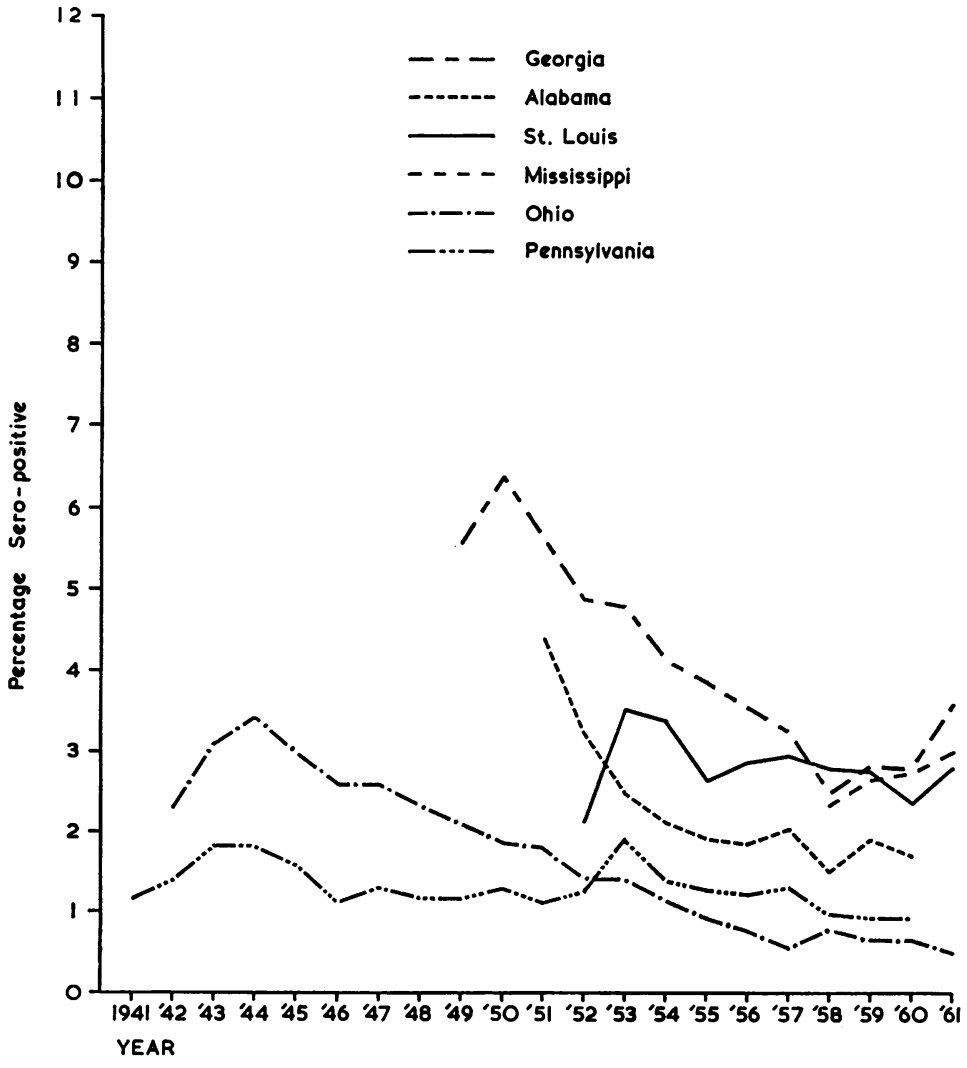

FIG. 2.-Pre-marital syphilis sero-positivity rates per cent. in five tates and one city, up to 1961 .

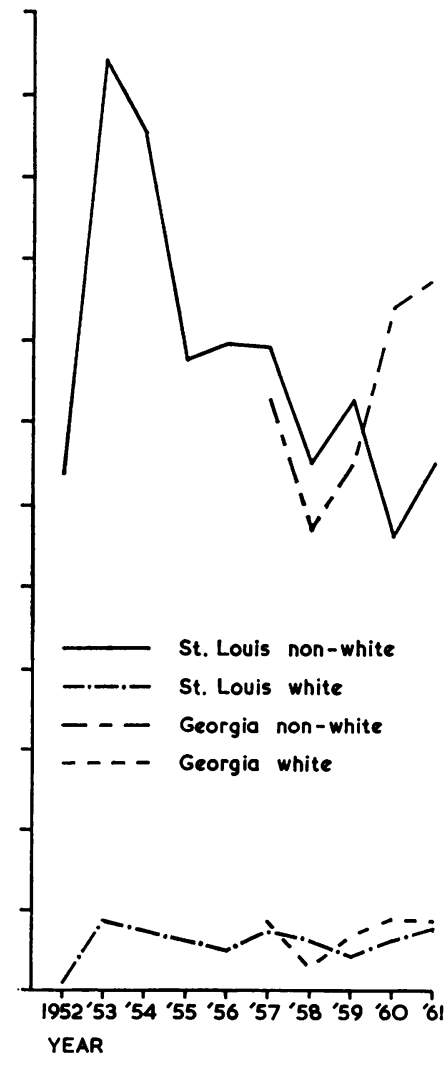

FIG. 3.-Pre-marital syphilis sero-positivity rates in St. Louis, Missouri, (1952-61) and in Georgia (1957-61), by race. 
Mississippi and Georgia has it risen appreciably since 1958. The level remained essentially stationary during this period in Alabama, Pennsylvania, Ohio, and the city of St. Louis, Missouri.

None of the rates given in Fig. 2 is broken down by race. This introduces a major potential error. A rate derived by throwing together a high non-white rate and a low white rate may show a fall despite a rise in both white and non-white rates, if the ratio of non-white to white persons decreases.

For example, the sero-positivity rate for 1,000 nonwhites with a rate of 10 per cent. and 1,000 whites with a rate of 1 per cent. is $5 \cdot 5$ per cent. $(100+10=110 ; 110$ in $2,000=5 \cdot 5$ per cent.). If the non-white rate rises to 12 per cent. and the white rate to 2 per cent., but the populations change to 500 non-whites and 1,500 whites, the overall rate falls to $4 \cdot 5$ per cent. ( 12 per cent. of 500 plus 2 per cent. of $1,500=60+30=90$. 90 in $2,000=$ $4 \cdot 5$ per cent.).

However, in Georgia and the city of St. Louis, Missouri (State Depts. of Health, 1962), the only areas where a race breakdown of the pre-marital rate is available, the white and non-white rates pursued trends similar to the overall rate (Fig. 3, previous page).

Theoretically, pre-natal serological tests where required by law should provide a more random sample, since pregnancy may occur without marriage. However, in Ohio, the pre-natal tests amounted to only 75 to 80 per cent. of the number of live births and in Pennsylvania to 50 to 65 per cent. In St. Louis, pre-natal tests are reported only from clinics for the indigent and represent only 5 to 10 per cent.

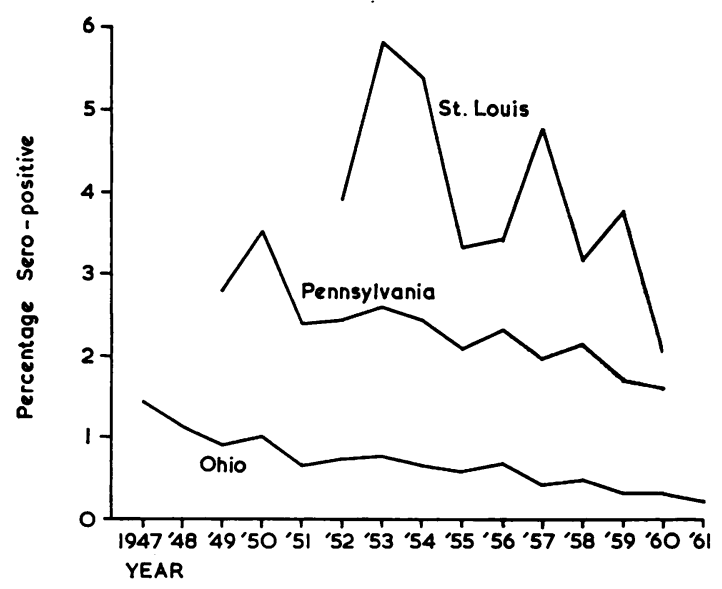

FIG. 4.-Prenatal syphilis sero-positivity rates per cent. in two states and one city, up to 1961 . of the total live births (Shapiro, 1962). Therefore, the pre-natal sero-positive rates for these three areas (Fig. 4) are not drawn from a random sample. As may be noted, however, a consistent decline is seen in all three.

In view of the great disparity between white and Negro venereal disease incidence and prevalence rates (Schamberg, 1956), the following observations may be pertinent. From 1940 to 1960 , the white population increased by 34 per cent. from 118.4 to 158.8 million and the Negro population by 49 per cent., from 13.8 to 20.5 million (U.S. Statistics, 1961). From 1940 to 1958 the white birth rate (live births per 1,000 women aged 15 to 44$)$ rose 26 per cent. $(18.6$ to 23.4$)$ and the Negro birth rate 28 per cent. (26. 7 to $34 \cdot 2)$ (U.S. Statistics, 1961). From 1940 to 1950 the white illegitimate birth rate (per 1,000 unmarried females age 15 to 44$)$ rose 69 per cent. (3.6 to $6 \cdot 1)$ and the Negro rate 100 per cent. $(35 \cdot 6$ to $71 \cdot 2)$ (U.S. Statistics, 1961). The already high legitimate and illegitimate birth rates in the Negro rising at a faster rate than in the white, combined with a faster rate of population growth, would tend to produce per se an overall rise in the venereal disease rate. However, the 94 per cent. decline in the syphilis rate during part of the period suggests that other factors played a more important role in the recent rise.

Despite the somewhat conflicting evidence, we feel there has been a true increase in the incidence of syphilis since 1957. Any change in an incidence rate is a function of the sum of the forces favouring the spread of the disease and those limiting such spread. We construe the reverse J curve from 1947 to 1961 in Fig. 1 to be the graphic result of the sum of these forces. To pinpoint the causes of the recent resurgence it is necessary to demonstrate the inhibition or disappearance of the "limiting factors" operating in the 1947-57 decade, or to find newly operating "spread factors" strong enough to neutralize and then overwhelm the "limiting factors" previously operating.

This presentation confines itself to consideration of four factors. The first two (greater sexual promiscuity, especially in teenagers, and more male homosexual activity) have been widely blamed for the recent increase in syphilis. A third influence, we suggest, may be a decrease in sensitivity of the treponeme to penicillin, and a fourth influence is the effect of so-called "happenstance" or coincidental administration of penicillin for other conditions to patients with unrecognized early syphilis (Schamberg, 1956). We have drawn together data from a variety of sources and recognize that there is contradiction on a number of points. 


\section{(1) Promiscuity and the Teenager}

An increase in sexual promiscuity, especially among juveniles, has been offered in many quarters as an explanation for the recent rise in the reported attack rate of syphilis. Recent comments include:

"We are particularly disturbed at evidence of a chain reaction in the spread of syphilis infection, especially among teenagers (U.S. Dept. of Health, 1962).

\footnotetext{
"There has been a consistent increase in the number of venereal disease cases reported among persons 19 years of age and under" (Association of State and Territorial Health Officers, etc., 1962).
}

In 25 states and in 36 cities Health Officers reported an increase in infectious syphilis among 15 to 19-year-olds (Ass. State and Terr. Health Officers, etc.). Prebble (1962), comparing the percentage of teenagers with venereal disease in 1935 and 1960 in two Liverpool venereal disease clinics, found male teenager patients increased from $2 \cdot 7$ to $9 \cdot 8$ per cent. and females from 8.6 to 22.4 per cent., and concluded that "young people to-day are more promiscuous than their parents were a quarter of a century ago".

What evidence is there for recent change in the basic behaviour pattern of the teenager? The studies of Kinsey, Pomeroy, and Martin (1948), Kinsey, Pomeroy, Martin, and Gebhard (1953) and Deschin (1961) are our only sources of quantitative investigation on this subject, and the latter provides data only for a fixed point in time, 1959. In the study of the male (Kinsey and others, 1948), Kinsey attempted to evaluate stability in patterns of sexual behaviour between successive generations based on interviews carried out from 1938 to 1947 with men of all ages. He pointed out that many people believed such patterns to have changed considerably within the last generation or so and stated that:

"Some persons seem to find a masochistic satisfaction in believing that the world is continuously more evil. If it were not for the fact that there have been similar Cassandras throughout the history of the world, one could almost be persuaded to believe that these persons possess scientifically adequate data on the sexual behaviour of previous generations which they have been able to compare with equally adequate data on the behaviour of the present generation. Nine years of research has failed to disclose statistically sound data which would justify any objective comparison of the behaviour of any previous generation with the present one."

Kinsey divided his male sample into two groups, those aged 33 years or over at the time they contributed their histories, and those younger than 33 .
Comparison of these two groups showed that they were almost identical in most respects. He concluded that:

"The sexual patterns of the younger gəneration are so nearly identical with the sexual patterns of the older generation in regard to so many types of sexual activity that there seems to be no sound basis for the widespread opinion that the younger generation has become more active in its socio-sexual contacts. . . . The charge more often concerns pre-marital intercourse with companions and with prostitutes, and homosexual contacts. On all of these latter points, however, the records for the older and younger generation are, by the admission of the older generation when it contributes its own histories, so nearly identical that no significant differences can be found. These questions are of such social significance that it is high time that scientific data replaced the loose statements and easy conclusions drawn by persons who find some sort of advantage in bewailing the ways of the world."

In the study of the female, based on interviews carried out between 1938 and 1949 (Kinsey and others, 1953), the subjects were separated into four chronological groups, those born before 1900 and those born in each of the first three decades of the 20th century. An increase in the incidence of heterosexual petting and pre-marital and extra-marital coitus was found among females born after the turn of the century in comparison with those born before 1900. Such activities had continued on the new levels or had kept rising in those born in each successive decade. The greatest increase was noted in petting and pre-marital coitus. Kinsey ascribed these changes to many factors, including the development of public interest in the works of Havelock Ellis and Sigmund Freud, the emancipation of the female in American culture, the contact of American soldiers in World War I with foreign cultures with different sexual patterns, the increased knowledge of contraception, the increase in the proportion of persons living under the greater anonymity provided by urban centres, and the decrease in organized prostitution. He found no evidence that either the depression of the 1930s or the introduction of penicillin had contributed to these changes:

\footnotetext{
"There has been little recognition that the pre-marital petting and coital patterns which were established in the 'roaring twenties' are still with us. To-day older persons seem less disturbed about the younger generation than they were in the '20s. The reason seems patent if we realize that the parents and grandparents of to-day were the youth who introduced the new patterns of sexual behaviour 30 years ago."
} 
Fig. 5 shows no recent increase in teenage early syphilis or male gonorrhoea expressed as a percentage of all ages, in either whites or non-whites.

It may be concluded, on the basis of the above admittedly scanty data, that:

(a) There is no evidence at hand to demonstrate a recent increase in teenage promiscuity.

(b) The teenager's share of venereal disease has not increased.

(c) Increase in population and in the relative number of non-whites in the population contribute to the increase in venereal disease in the younger Americans.

\section{(2) The Male Homosexual}

A dramatic change in the epidemiological picture of syphilis has occurred within the last decade. The author worked in the syphilis clinic (Medicine I) at Johns Hopkins Hospital in the late '30s and early '40s and at that time saw much early syphilis, but was only very rarely aware of male homosexuals in the clinic. Hahn (1962) and Clark (1962) confirm this observation. Within the past 10 years many syphilologists and public health workers have found the male homosexual to be an important factor in the transmission of both syphilis and gonorrhoea. Health personnel in 33 states and 64 cities, primarily in large industrial areas in coastal and border states, recently stated that homosexual activity was contributing an increasing percentage of venereal disease cases. In 14 states and in 33 cities one-fifth or more of male patients with primary or secondary syphilis named male contacts (Ass. State Terr. Hith Offrs, etc., 1962). Tarr (1962) reported that 69 per cent. of males with primary or secondary syphilis in Los Angeles in 1959 admitted recent homosexual activity. In the same year, figures for Columbus, Ohio, and Richmond, Virginia, were 56 and 43 per cent. respectively. According to Tarr, Vancouver, British Columbia, reported 77 per cent. in 1957. Hahn (1962) stated that when he sees a while male with primary or secondary syphilis to-day this is practically synonymous with current overt homosexual activity. Nicol (1960) studying the incidence of homosexuals among new male patients at a London venereal disease clinic, found an increase from $1 \cdot 2$ per cent. in 1954 to 4.9 per cent. in 1959. Laird (1962) has recently reported that in at least one-third of male cases of early syphilis seen in Manchester and infected in the United Kingdom the disease was transmitted homosexually.

Touraine (1961) stated that in Paris the percentage of all anal chancres in males increased from 4.6 per cent. in 1951-53 to $18 \cdot 2$ per cent. in 1957-59, and that 22 per cent. of syphilitic infections in 1959 were transmitted by male homosexuals.

Many questions are raised by these startling observations. Is male homosexuality significantly more common to-day than 5 or 10 years ago? Is there more venereal disease in male homosexuals than there was in the past, or is it simply that venereal disease is more frequently diagnosed in such patients? Is it possible that male homosexuals attend veneral disease clinics in greater numbers than in the past and are therefore subjected to a greater
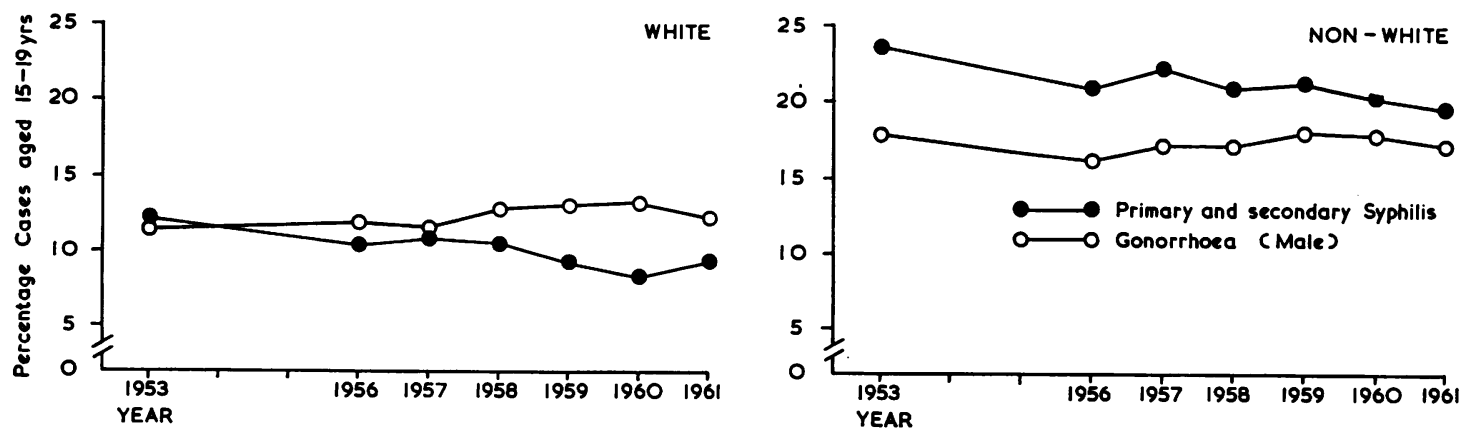

FIG. 5.-Incidence of primary and secondary syphilis and of male cases of gonorrhoea in persons aged 15-19 years in whites and non-whites, as a percentage of all ages in the U.S.A., in 1953 and 1956-61. 
extent to contact interviews which reveal the existence of additional venereally-infected homosexuals? Is the male homosexual to-day more promiscuous than he was in the past? And finally, since one is most likely to find what one is looking for, is the male homosexual with venereal disease more frequently identified to-day as a homosexual because of a higher index of suspicion?

Kinsey and others (1948) reported that 10 per cent. of the males interviewed between 1938 and 1947 had been predominantly homosexual for 3 years or more, and that 37 per cent. had had at least one homosexual encounter after the onset of adolescence. They found no difference in percentage of homosexuals, nor in the frequency of homosexual activity, between men under 33 years of age at the time of interview and those aged 33 years and over, nor between females born in four different decades (Kinsey and others, 1948, 1953).

In the abundant sociological and psychiatric literature on homosexuality, opinions are far more plentiful than facts. Kardiner (1954) believed that there had been a recent increase in the number of male homosexuals and put forth a number of plausible reasons for it. He stated that the feminist movement made women competitors and stepped up the requirements of masculinity, which in to-day's world was often found to be a difficult or unattainable ideal.

"We live in a culture in which opportunity to exercise maleness is periodically curtailed by depressions, war, and threats of war. Money, economic power, and prestige are associated to-day with sexual potency, so that lack of these crushes the feeling of maleness."

Homosexuals are overwhelmed by demands to fulfil the male role, and flee from competition because they fear pressure on what they consider their limited resources. Women are a threat rather than a solace because they expect maleness. Dagwood Bumpstead*, the child husband who is rescued by his wife from repeated difficulties of his own making and pays for this by loss of dignity, Kardiner cites as a prototype. Men such as these have "a tenuous hold on masculinity" and may become homosexual even late in adult life if they encounter stresses such as unemployment, failure in business, battlefield ordeals, deprivation, or association with dominant women. He concluded that increase in homosexuality is a symptom of grave social dislocation and is a part of the price exacted by the pressures of western civilization to-day.

* A newspaper comic strip character widely known to children and adults throughout the U.S.A.
Westwood (1960), who carried out a detailed sociologic study on 127 British homosexuals, and Berg and Allen (1958) felt that insufficient evidence was at hand to indicate any recent increase in male homosexuality. Schwartz (1962) and Wolfgang (1962) agree that determination of the frequency of a phenomenon such as homosexuality requires far more detailed data than we now possess.

Fig. 6 reveals a recent striking increase in the male : female ratio of primary and secondary syphilis in white patients in the United States, with essentially no change in the non-white. Laird (1962) found a similar picture in whites in Great Britain, the male : female ratio having increased from $1 \cdot 6: 1$ in 1948 to $4 \cdot 7: 1$ in 1960 . He pointed out that infection of males overseas and by local prostitutes, and homosexual infection of the male could all cause such an increase in the male : female ratio. In the United States the most probable factor is an increase in homosexuality. The steadiness of the ratio in the non-white may be due to the higher level of heterosexual promiscuity, which overshadows and obscures changes in the ratio due to male homosexual transmission.

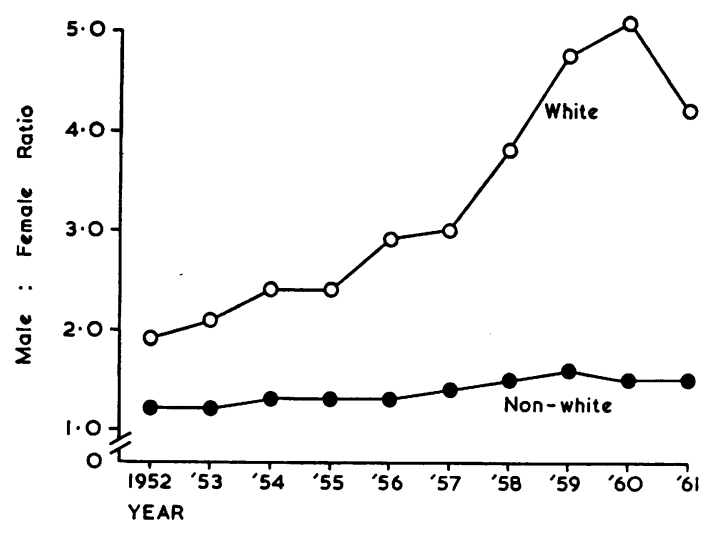

Fig. 6.-Male : Female ratio of reported cases of primary and secondary syphilis in the U.S.A. by race, 1952-61.

We have attempted to view this problem from a number of different angles, and have found conflicting opinions and little factual data. The consensus appears to be that there is no clear evidence of a major recent increase in homosexuality or in homosexual promiscuity. The intrusion of the homosexual on the venereal disease scene requires elucidation.

Parenthetically, it is of interest that the "Matachine Society", an organization of male homosexuals with 
headquarters in San Francisco, has associated organized groups in New York, Philadelphia, Boston, Chicago, Denver, and Richmond. "One, Incorporated", a similar group, originated in Los Angeles, and the "Daughters of Bilitis, Inc.", a nationwide society of lesbians, has headquarters in San Francisco. There is also a Homosexual League of New York. Some of these, notably the Mattachine group in New York City, put out regular monthly mimeographed newsletters which closely resemble those of more prosaic social organizations.

\section{(3) Sensitivity of $T$. pallidum to Penicillin.}

It is a universal law of nature that all living things, in order to survive, must have the potential for change to combat an unfavourable environment. Penicillin creates such an unfavourable environment for the treponeme. Eagle, Magnuson, and Fleischman (1946) demonstrated in 1946 that 90 per cent. of rabbits were cured of syphilis by as little as 500 units per $\mathrm{kg}$. when treated on an optimal timedose schedule. Is it possible that the sensitivity of the treponeme to penicillin has decreased and that this may play a part in the recent increase in syphilis? The least sensitive gonococci isolated from patients in 1960 required twenty times the concentration of penicillin required by the least sensitive organisms isolated in 1944 (Anderson, 1962).

Our inability to grow $T$. pallidum outside the mammalian body precludes the simple in vitro sensitivity determinations used for the gonococcus and other organisms. The only methods of detecting a similar decrease in sensitivity of the treponeme would be by demonstration of an increase in the MCD (minimum curative dose) in rabbits infected with recently isolated strains of treponemes, or of an increase in the relapse rate in patients treated for primary or secondary syphilis as compared with that observed during the 1940 s. The latter would require a large group of patients treated with identical doses of penicillin and followed carefully by skilled clinical syphilologists for 1 to 2 years. Such an evaluation has not been made since the initial Nationwide Study of Early Syphilis (Committee on Medical Research, 1946) was carried out during and immediately after World War II.

The marked variation in penicillin blood levels in different patients (and even in the same patient after successive injections of identical amounts of penicillin (Pellerat, Maillard, and Carron, 1961) may cause sub-curative concentrations in many patients. In addition, the prolonged low-level "tail" which follows the injection of long-lasting penicillin preparations also brings the treponeme into contact with sub-curative concentrations. Reyn, Korner, and Bentzon (1958) have suggested that such sub-lethal concentrations may have been a cause of the decrease in sensitivity of the gonococcus to penicillin. It appears likely that a similar effect might occur in the treponeme.

The study made by Eagle and others (1946) should be repeated with newly-isolated strains of treponemes in order to demonstrate whether or not the MCD of penicillin is now greater than it was in the mid-' 40 s.

\section{(4) Decrease in Penicillin Usage}

Before the penicillin era therapy for syphilis awaited diagnosis (Schamberg, 1956), and months or years might elapse between infection and diagnosis and treatment. The long incubation period and the mild or even symptomless early stages tended to lengthen this interval. In the first decade after the introduction of penicillin it is probable that many persons recently infected with syphilis received penicillin for another disease before the time when a diagnosis of syphilis could and would have been made. Since most patients in the incubation period of syphilis, as well as those in the primary and secondary stages, are curable by the dosage usually given for other diseases, the syphilitic infection, of which both doctor and patient were unaware, was often cured. The development of increasingly effective repository preparations, whereby a blood level adequate to kill the treponeme was maintained for days or even weeks, increased the likelihood of cure of early syphilis by such coincidental treatment. By this mechanism the duration of infectiousness was cut short, often to hours or days, transmission of infection was curtailed, and the number of new cases fell.

"If 'happenstance' penicillin has been the important factor (in the decrease in syphilis), we can anticipate a rise in the attack rate. Because of the increasing number of serious and even fatal reactions, and because a number of bacteria have developed penicillin resistance, utilization of penicillin will probably decrease in this country within the next few years, physicians turning more and more to the broad-spectrum antibiotics which are not as effective against syphilis as is penicillin" (Schamberg, 1956).

Is there evidence that this prophecy has come true? Have warnings such as that of Flippin (1961) borne fruit in discouraging the use of penicillin?

"For the sake of the patient and the legal implications
to the physician, it may be best to abandon the use of
penicillin except where proper studies indicate it to be the 
only effective drug for the treatment of a specific infection."

The Table and Fig. 7 present the best available estimate of production of penicillin for human and veterinary use in the United States from 1949 to 1961 and of broad-spectrum antibiotics (plus polymyxin and tyrothricin) from 1948 to 1960 (U.S. Tariff Commission, 1946-60). Unfortunately, it was not possible to exclude antibiotics used in veterinary medicine nor those exported. However, antibiotics used for animal feed supplements, food preservation, and crop spraying have been excluded. Average medicinal penicillin production increased by only 4 per cent. from the 5-year period 1951 to 1955 $(627,000 \mathrm{lb}$.) to the 5-year period 1956 to 1960 $(653,400 \mathrm{lb}$.) The corresponding figures for medicinal broad-spectrum antibiotics show an increase of 110 per cent. from 467,600 to $978,200 \mathrm{lb}$., and the population rose by 19 per cent. from 151 million in 1950 to 178 million in 1960 (U.S. Statistics, 1961).

TABLE

PRODUCTION OF MEDICINAL GRADES OF PENICILLIN AND BROAD-SPECTRUM ANTIBIOTICS* $(1,000 \mathrm{lb}$.)

\begin{tabular}{|c|c|c|c|c|}
\hline \multirow[b]{2}{*}{ Year } & \multicolumn{4}{|c|}{ Production (1,000 lb.) } \\
\hline & Penicillin & $\begin{array}{c}\text { 5-yr } \\
\text { Average }\end{array}$ & $\begin{array}{c}\text { Broad- } \\
\text { Spectrum } \\
\text { Antibiotics }\end{array}$ & $\begin{array}{c}\text { 5-yr } \\
\text { Average }\end{array}$ \\
\hline $\begin{array}{l}1948 \\
1949 \\
1950\end{array}$ & $\begin{array}{l}161 \\
249 \\
429\end{array}$ & & $\overline{\overline{2}}$ & \\
\hline $\begin{array}{l}1951 \\
1952 \\
1953 \\
1954 \\
1955\end{array}$ & $\begin{array}{l}625 \\
671 \\
753 \\
631 \\
455\end{array}$ & 627 & $\begin{array}{l}307 \\
414 \\
441 \\
597 \\
579\end{array}$ & 468 \\
\hline $\begin{array}{l}1956 \\
1957 \\
1958 \\
1959 \\
1960\end{array}$ & $\begin{array}{l}631 \\
694 \\
516 \\
567 \\
859\end{array}$ & 653 & $\begin{array}{r}697 \\
869 \\
1,314 \\
932 \\
1,079\end{array}$ & 978 \\
\hline
\end{tabular}

* Including Polymyxin and Tyrothricin.

Fig. 8 (opposite) shows some examples of the increase in the recommended dosage of penicillin for a wide variety of disease from 1950 to 1961 (Merck, $1950,1956,1961)$. Penicillin production has increased by only 4 per cent., the population has risen 19 per cent. and penicillin dosage per patient has increased many-fold. Therefore, the percentage of the population which received no penicillin in a given period of time in 1960 is much greater than it was in 1950. The dosage per patient of the broad-spectrum antibiotics has not increased, primarily because the gastrointestinal side-effects usually prevent dosage much higher than one g. per day. Since production has

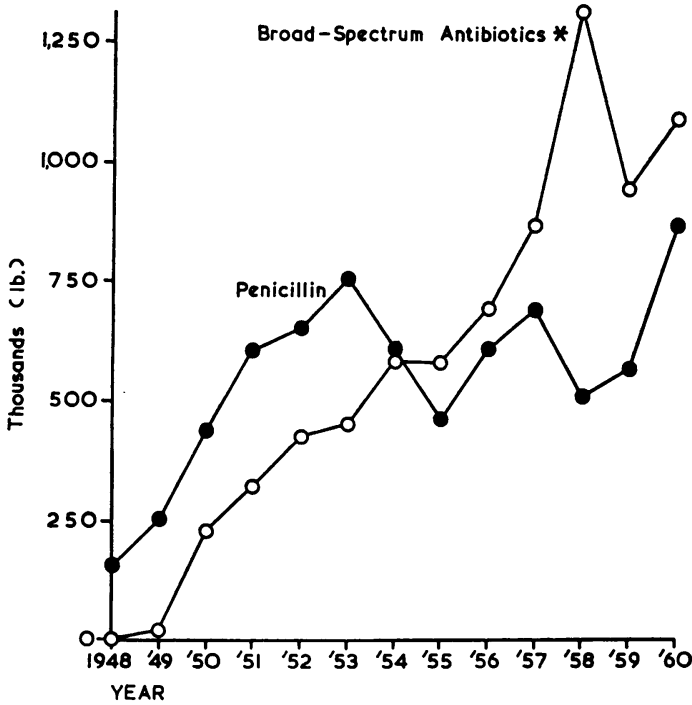

FIG. 7.-Approximate annual production (in thousands of lb.) of medicinal grades of penicillin and broad-spectrum antibiotics in the United States, 1948-60. Figures from U.S. Federal Tariff Commission.

more than doubled from the previous 5 years, it would appear that over twice as many infections are now being treated with the broad-spectrum antibiotics which, in the usual dosage, are far less effective than penicillin against syphilis. Thus there is now less opportunity for "happenstance" penicillin to effect an early cure of an unrecognized syphilitic infection and thus abbreviate the period of infectiousness.

Magnuson (1955) suggested some years ago that the continued high gonorrhoea attack rate may have been a factor in lowering the syphilis attack rate, through the administration of penicillin for gonorrhoea to a large number of persons in the socioeconomic, ethnic, and age groups in which syphilis most frequently occurred. Willcox (1962) has recently propounded a similar thesis. For such a mechanism to be effective a vigorous public health effort against gonorrhoea would be necessary, in order to bring the largest possible number of gonorrhoea patients and contacts to penicillin therapy. At present, because of the increased epidemiologinal manpower needed to fight early syphilis, gonorrhoea has again become the step-child it was for so many years. In many public health clinics epidemiological activity in gonorrhoea has slackened. Current practice in the health department of a large eastern city (Lentz, 1962) is to give epidemiological priority to early 


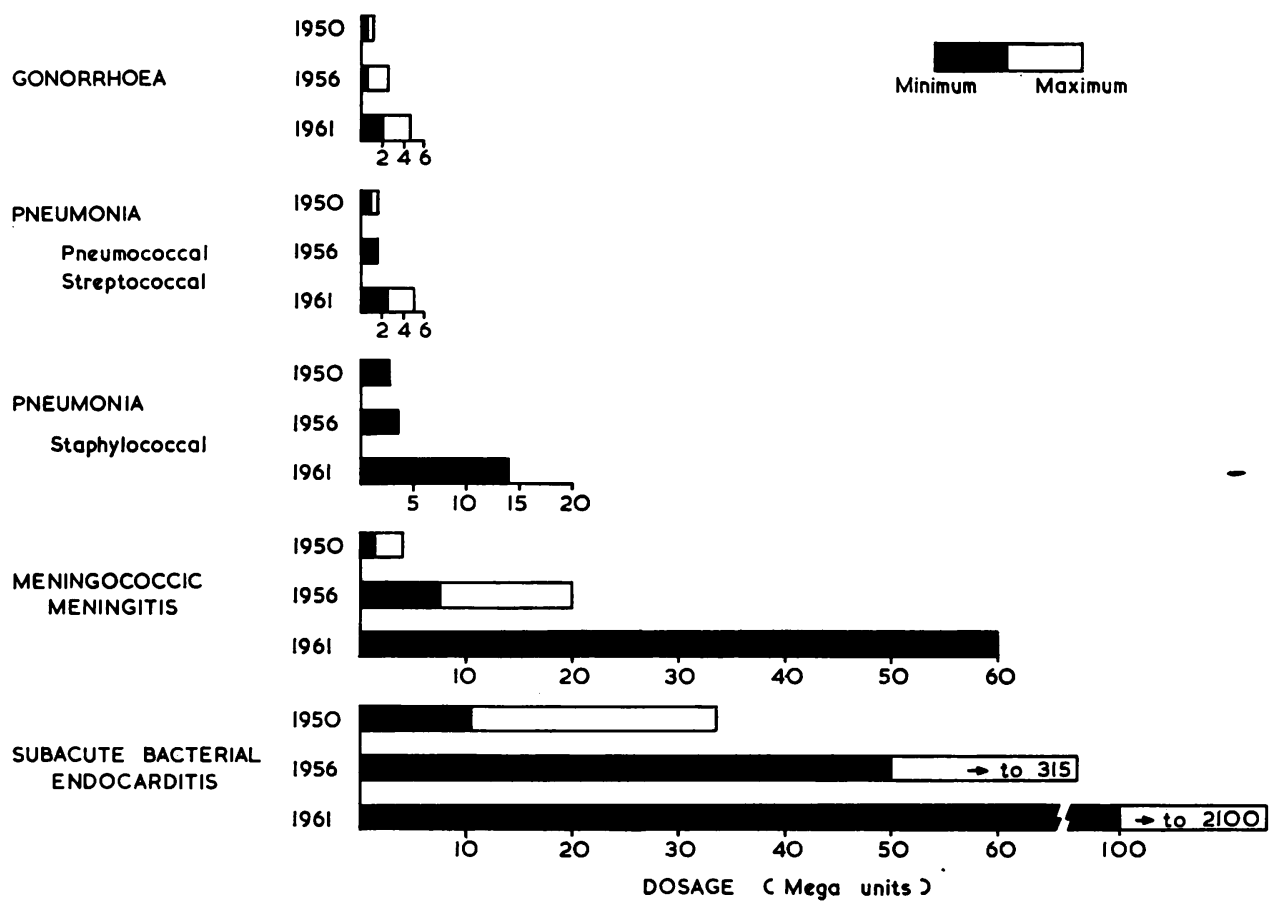

Fig. 8.-Recommended maximum and minimum dosages of penicillin for five diseases according to the "Merck Manual" in 1950, 1956, and 1961.

syphilis, the contact interview taking 20 to 30 minutes. If enough time remains, male patients with gonorrhoea are interviewed for about 5 minutes in an attempt to obtain only the name of the wife and steady sex partner. He is given appointment cards to give to these contacts, and if they do not report to the clinic within 3 days a telegram is sent. When the press of interviewing patients with early syphilis is so great that not even 5 minutes can be spared for the gonorrhoea patient, he is given appointment cards by the clinic nurse and asked to bring or send in his recent sex partners. If Magnuson's hypothesis is correct, we are now witnessing a vicious cycle-the more early syphilis encountered the less epidemiological effort is devoted to gonorrhoea, and the fewer gonorrhoea contacts found and treated with penicillin the less "happenstance" penicillin will be received by the group most in need of it, and the fewer cases of early syphilis will be aborted.

We believe that decrease in the utilization of penicillin for non-syphilitic infections has played a major role in the resurgence of syphilis. Treatment of sero- negative and clinically negative recent contacts of patients with primary and secondary syphilis, a public health measure now in wide use designated as epidemiological treatment, is the only method, other than "happenstance" penicillin, which reaches syphilis and renders it non-infectious within hours or days after infection. To wait to treat the disease until it has been diagnosed is to permit it to remain infectious for at least 3 weeks, and often for many months. This allows ample opportunity for dissemination to many sex partners. The more promiscuous the infectious patient, the more widely will he spread his disease before he is diagnosed and treated.

No matter how skilled and dedicated the epidemiological investigator may be, he cannot learn of every contact, nor can he find and bring to diagnosis and treatment every named contact. How then, may we reach these thousands scattered through a population of 180 millions, who are faceless in the crowd? Ever changing, yet ever present, their syphilitic infection unknown to themselves, their sex partners, their physicians, and their health departments, they 
are the unidentified spreaders of disease. Their treatment is the key to the control of the great pox.

\section{Summary and Conclusions}

After a 94 per cent. decline in reported cases of primary and secondary syphilis in the United States from 1947 to 1957 , the numbers increased more than three-fold between 1957 and 1962.

Four possible reasons for this resurgence are discussed:

(1) Increased promiscuity of the teenager.

(2) Increased numbers of overt male homosexuals and an increase in their sexual activity.

(3) Decreased sensitivity to penicillin of $T$. pallidum.

(4) Decreased use of penicillin in non-syphilitic infections.

On the basis of present evidence the role of the first three factors cannot be evaluated.

The fourth factor appears to have played a major part in the resurgence of syphilis. The decreased use of penicillin in the last 7 years has lessened the likelihood of curing infectious syphilis by coincidental treatment. Except for epidemiological treatment of the contacts of patients with early syphilis, this is the only means of shortening the infectious period to hours or days, since specific treatment for syphilis must await diagnosis, which always requires weeks, and may require months or years.

I am deeply indebted to Dr. William F. Danehower for his invaluable assistance in the preparation of this paper.

\section{REFERENCES}

Anderson, T. (1962). Personal communication.

Association of State and Territorial Health Officers, American Venereal Disease Association, and American Social Health Association (1962). "Today's V.D. Control Problem. A Joint Statement". New York.

Berg, C., and Allen, C. (1958). "The Problem of Homosexuality". Citadel Press, New York.

Clark, E. G. (1962). Personal communication.

Committee on Medical Research and the United States Public Health Service (1946). J. Amer. med. Ass., 131, 265.

Deschin, C. S. (1961). “Teen-agers and Venereal Disease. A Sociological Study of 600 Teen-agers in New York City Social Hygiene Clinics". U.S. Department Health, Education and Welfare, Government Printing Office, Washington, D.C.

Eagle, H., Magnuson, H. J., and Fleischman, R. (1946). Bull. Johns Hopk. Hosp., 79, 168.

Flippin, H. F. (1961). Penn. med. J., 64, 1578.
Guthe, T. (1962). "Measure of the Treponematosis Problem in World To-day". Paper presented at the World Forum on Syphilis and Other Treponematoses, Washington D.C., Sept. 4, 1962.

Hahn, R. D. (1962). Personal communication.

Kardiner, A. (1954). "Sex and Morality”. Bobbs-Merrill, Indianapolis.

Kinsey, A. C., Pomeroy, W. B., and Martin, C. E. (1948). "Sexual Behavior in the Human Male". Saunders, Philadelphia.

- -1, - - and Gebhard, T. H. (1953). "Sexual Behavior in the Human Female". Saunders, Philadelphia.

Laird, S. M. (1962). Brit. J. vener. Dis., 38, 82.

Lentz, J. W. (1962). Personal communication.

McIntosh, J., and Fildes, P. (1910). Lancet, 2, 1684.

Magnuson, H. J. (1955). Personal communication.

Mahoney, J. F., Arnold, R. C., and Harris, A. (1943). Vener. Dis. Inform., 24, 355.

Meltzer, S. J. (1910). N. Y. med. J., 92, 371.

"Merck Manual" (1950, 1956, and 1961). Merck and Co. Inc., West Point, Pa.

Nicol, C. S. (1960). Practitioner, 184, 345.

Pellerat, J., Maillard, M. A., and Carron, R. (1961). Brit. J. vener. Dis., 37, 252.

Prebble, E. E. (1962). Ibid., 38, 86.

Reyn, A., Korner, B., and Bentzon, M. W. (1958). Ibid., 34, 227.

Schamberg, I. L. (1945). Amer. J. Syph., 29, 529. (1956). A.M.A. Arch. Derm., 73, 523.

Schwartz, L. B., Professor of Law, University of Pennsylvania (1962). Personal communication.

Shapiro, J. (1962). Personal communication.

State Depts. of Health (1962). Personal communication. Tarr, J. D. F. (1962). G.P., 25, 91.

Touraine (1961). Rev. Hyg., p. 474, (reviewed by F. Deniker (1961) Sem. med. Prof., 37, 792.

U.S. Dept. of Health (1962). "The Eradication of Syphilis. A Task Force Report". U.S. Department of Health, Education and Welfare, Public Health Service.

U.S. Navy Dept. (1962). Statist. Nav. Med., 18, No. 4, p. 41 .

U.S. Statistical Abstracts of the United States (1961). Bureau of the Census, United States Government Printing Office, Washington, D.C.

U.S. Tariff Commission. Synthetic Organic Chemicals, U.S. Production and Sales. Medicinals. 1946 to 1960 (except 1948, 1950, and 1956).

Westwood, G. (1960). "A Minority. A Report on the Life of the Male Homosexual in Great Britain". Longmans, Green, London; Clark, Edinburgh.

Willcox, R. R. (1962). Brit. J. vener. Dis., 38, 189.

Wolfgang, M. E. Associate Professor of Sociology, University of Pennsylvania (1962). Personal communication.

\section{La Syphilis et Sisyphus RÉSUMÉ}

Après la chute du taux des cas de syphilis précoce ct secondaire rapporté aux Etats Unis entre 1947 et 1957, le nombre augmenta trois fois entre 1957 et 1962.

On discute quatre raisons pour cette récrudescence:

1. L'augmentation de la promiscuité sexuelle parmi les jeunes gens. 
2. L'augmentation de l'homosexualité manifeste parmi les hommes.

3. La diminution de la sensıbilité du $T$. pallidum à la pénicilline.

4. La diminution de l'emploi de la pénicilline contre les infections non-syphilitiques.

On ne peut pas constater le rôle actuel des trois premiers, mais il parait que le quatrième à fait une assez grande contribution à la résurgence de la syphilis.
L'emploi diminué de la pénicilline pendant les sept dernières années a rendu moins probable le guérison coincidentale de la syphilis infectieuse.

Sauf le traitment epidémiologique des consorts sexuels des gens atteints de la syphilis précoce, celui-ci est le seul méthode d'abréger l'infectivité; le traitment spécifique doit attendre le diagnostic, et ce dernier demande toujours des semainis et qualquefois même des mois ou des années. 